\title{
Analysis of the Visual Aesthetic Mode of Zhu Ming's Art Museum from Its Spatial Layout
}

\author{
Yuanyuan $\mathrm{Hu}$ \\ School of Arts \\ Southeast University \\ Nanjing, China 210000
}

\begin{abstract}
The article aims to explore how artistic work can be presented in the context of museums under the visual arts. How does the recipient touch the work of art, and get close to the mystery of art? Recipients can "sightsee", "stare", and "appreciate" the art works through the space created by the museum to open the mystery of art. The author believes that the spatial arrangement of Zhu Ming's Art Museum construct the aesthetic way of "up-and-down observation", and "sightseeing" and in the way of "up-and-down", "sightseeing", and "staring", the artistic recipients can approach the works of art and understand the art, to understand the author's humanistic feelings, such as the culture of "etiquette" reflected in the "the man's world" series sculpture. Ultimately, the art recipients and art works can form interaction, so art culture can be spread and carried forward.
\end{abstract}

Keywords-Zhu Ming's Art Museum; space; visual aesthetic mode

\section{INTRODUCTION}

After the new cultural movement, Zong Baihua pays attention to the up-and-down observation of the world by ancient Chinese again, and he believes that the fundamental difference between Chinese art and Western art is that Chinese have been used the aesthetic care mode of up-anddown observation and combination of far and near. The source of formation of this unique aes thetic mode is from the up-and-down observation of world clearly proposed in the book "Book of Changes". That is, "looking up is to observe the sky, and looking down is to observe the land".

Zong Bing says in "preface of painting landscape": "Kunlun Mountain is so big while our eyes are small, so if we look at it closely, we can't know what it is like; if we look at it at a distance, we can see its profile." That is to say, the further the distance between you can the objective, the smaller you can see". "We observe the soul of the mountains and water by eyes and then comprehend it, so we can get the principle. Therefore, if the the picture is well painted, what we see and what the painter think should be the same" When he grows old and can't travel faraway, he signs: "when old and disease comes together, I'm afraid that I can't see all the famous mountains, so I should calm down to be enlightened by observing the pictures on the bed." "All the places where he traveled have been painted into picture and hung on the wall. He says to others: I play the guqin to make the sound echo between mountains."

"Mind travel" here of Zong Bing is lying on the bed to watch, which make the later generations compose the pictures by using scroll-type open mode for a long time when painting, and people also adopt the mode of "moving" to enjoy the picture, so the eyes of viewers move horizontally with the picture. Of course, when we make the "sightseeing", there are usually several kinds of viewing modes: horizontal watching, far back watching, upward watching, staring (gaze), and watching as looking at scroll painting and so on.

So can the viewer be able to walk in a different space when he or she is watching a work? This article discusses how the space design allows the recipient to get the aes thetic experience. The author takes the spatial layout of Zhu Ming's Art Museum as an example to study the visual aesthetic mode of its spatial layout.

The author thinks that the space of Zhu Ming's Art Museum mainly forms the visual aesthetic way of "up-anddown" and "sightseeing". In both visual ways, the recipient can interact with the artwork and obtain the aesthetic feeling, to understand the artwork itself.

\section{ANALYZE ZHU Ming'S ART MUSEUM BY WAY OF "UP AND DOWN"}

Why this the article takes Zhu Ming's Art Museum as an example to study the visual aesthetic way? How does the artist Zhu Ming let the recipient interact with the artwork in the context of art museum?

Artists are engaged in creation and collectors collect the works of artists. Zhu Ming is an artist who wants to collect his own works. In eighty-five year of the Republic of China, Zhu Ming began to build a cultural art park, and the name of this park located in Jinshan is changed to [Zhu Ming's Art Museum] in September in eighty-eight year. This venue accommodates almost all of the sculptures and paintings of Zhu Ming.

"The design here is most thorough, each grass and tree, materials, patterns, style, the size are my ideas ......" If his creation can be regarded as first-class work, Zhu Ming's Art Museum is his largest public space work. 
Zhu Ming put each of his unique works in the context of art museum, providing the audience with a different kind of visual space as shown in "Fig. 1".

The map of Zhu Ming's Art Museum

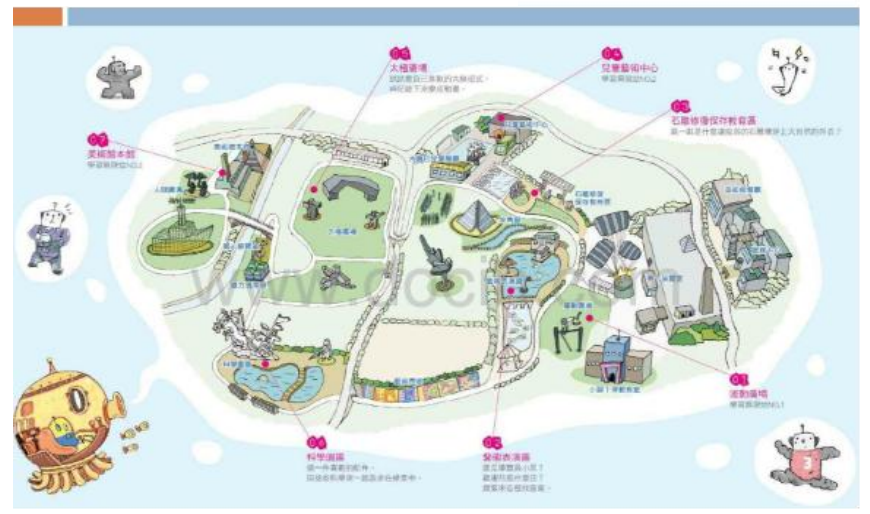

Fig. 1. The map of Zhu Ming's Art Museum.

Zhu Ming's Art Museum is located in the hillside of Jinshan District in Xinbei, Taiwan, near the mountain and by the river; Mr. Zhu Ming originally aimed to solve the problem of storage of large works, and later he found inspiration from nature, so he decided to build a garden to show his life masterpiece, and let the artist to play their creativity; according to different landscapes, Mr. Zhu Ming plan out the service center, first exhibition room, conference room, art performance area, art exchange area, Zhu Jun District, dabbling area, Tai Chi Square, art museum, human square, mother stele, swan pool, art gallery, and sports square.

Zhu Ming's Art Museum provides recipients with the space to integrate with the works, and the recipient can achieve the spread of art by way of "sightseeing". Zhu Ming's Art Museum as a large space sculpture, itself is a work. At the same time, this work can be used to display, collection, and exhibit. This is a special case in the current Chinese art museums, so the author uses it as a research object.

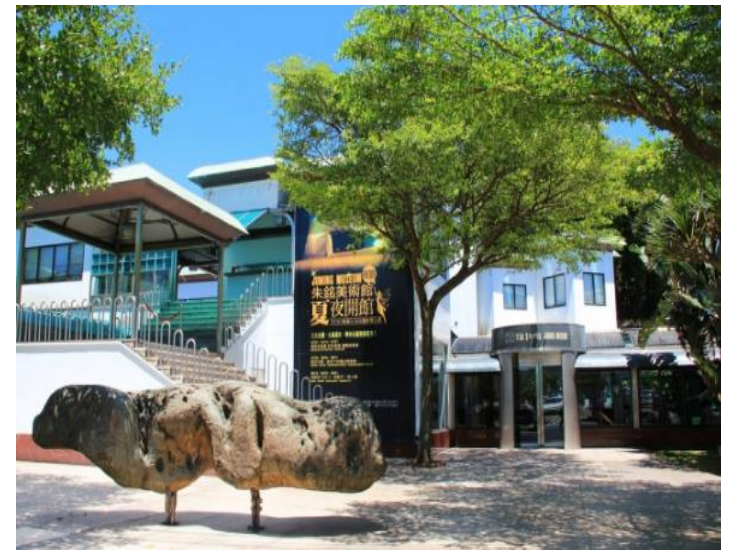

Fig. 2. Zhu Ming's Art Museum.

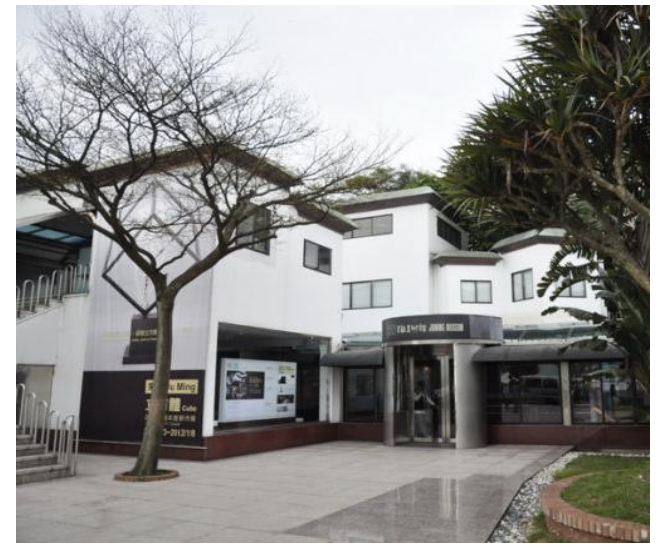

Fig. 3. Zhu Ming's Art Museum.

Taking the entrance of Zhu Ming's Art Museum as the starting point as shown in "Fig. 2" and "Fig. 3", it's hard for us to imagine that this is the gate of the international $\mathrm{Zhu}$ Ming's Art Museum when facing this simple front door, and we may be surprised: Do I go wrong?

Don't do as the author do since that two ordinary restaurants doors will soon take you into the secret area where the "seeds of art" bloom flowers. When we opened the door, and purchase the tickets, the journey of "sightseeing" the secret area is about to start. After entering the door, there is nothing novel before our eyes. What we can see is only the downward step in the corner, and then the fantasy trip of Edenso begins. This arrangement make people can't help thinking of the famous quotation in "the Pipa player": "Only after our repeated calls did she appear; her face still half hidden behind a pipa lute." We continue to move on with doubt. After walking through dozens of steps, what comes into view are the pasteup full of fashionable breath. Zhu Ming uses a variety of media, including colorful canvas, translucent plain cloth, opaque and monochrome fabric and so on to make overlapping collage, resulting in different space level as shown in "Fig. 4", "Fig. 5" and "Fig. 6". My eyes are walking with different spaces.

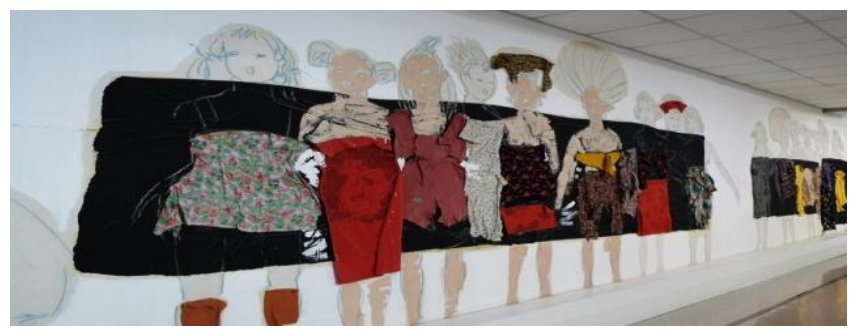

Fig. 4. The collage on both sides. 


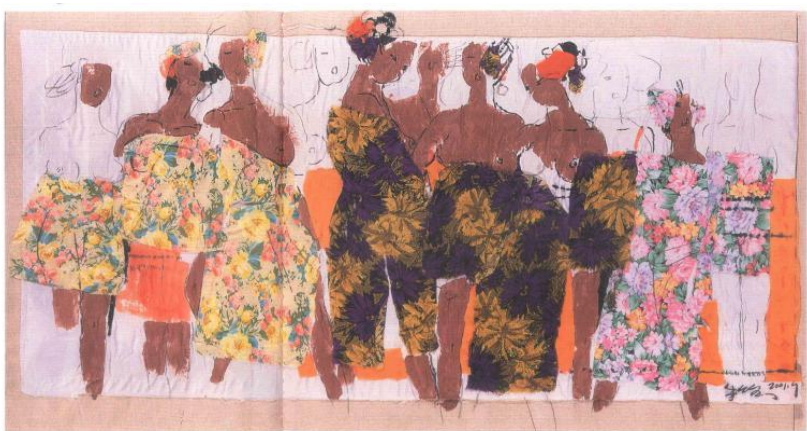

Fig. 5. The collage on both sides.

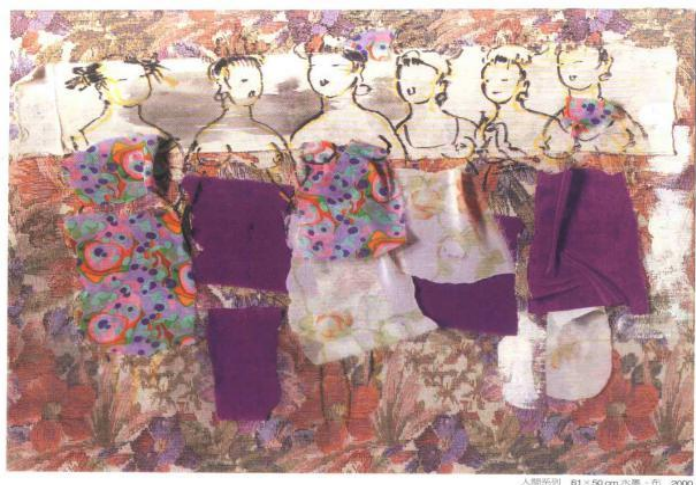

Fig. 6. The collage on both sides.

Traveling across the corridor, the door of the new world is opened for the tourists. The left is a spacious exhibition hall in the attic layout, and in the bottom of the glass frame collected sculptures of rural series of Zhu Ming. Then we walk up the stairs to see closet in various shapes, where there are the works of young artists' display of different stages. Standing above the attic, the big sculpture "work together" can be overlooked. The viewing effect of overlooking can make people, cattle, and car maintain a balance in join forces, revealing the connotation of the theme "work together" with the vision.

Out of the exhibition hall are the paratroopers hanging in the sky, which attract the viewers to look up. This group of people belongs to the "the series of the man's world - the army" in "Fig. 7" and "Fig. 8". Lovely paratroopers land in the building of the Taiwan Art Museum, like the pilots who are ready to rescue the trapped victims. Every audience entering the museum is bound to be attracted by this work, why? First of all, the position where it is placed determines. Secondly, the perspective provided by the author for viewers is unusual. As the previous "sightseeing" in Zhu Ming's Art Museum, after the aimless "sightseeing", the high placement immediately focus the dissociative eyes of the visitors on the flying men in sky, namely "gaze." "The core of the 'exhibition poetics' is that the unique intellectual property rights and power relationship in the exhibition ceremonies are quietly placed, which is the same in department stores and museums." So in the Zhu Ming's Art Museum, the

\footnotetext{
"To see or not to see - visual education in the era of picturereading" Wang Xin, New Star Press, 2014.6.
}

cultural knowledge of airborne troops is also placed into the hearts of the audience in this way. In the tour, the audience will look up at the mid-air sculpture, stare at the still gesture of flying men, and the spirit of paratroopers emerges in the brain.

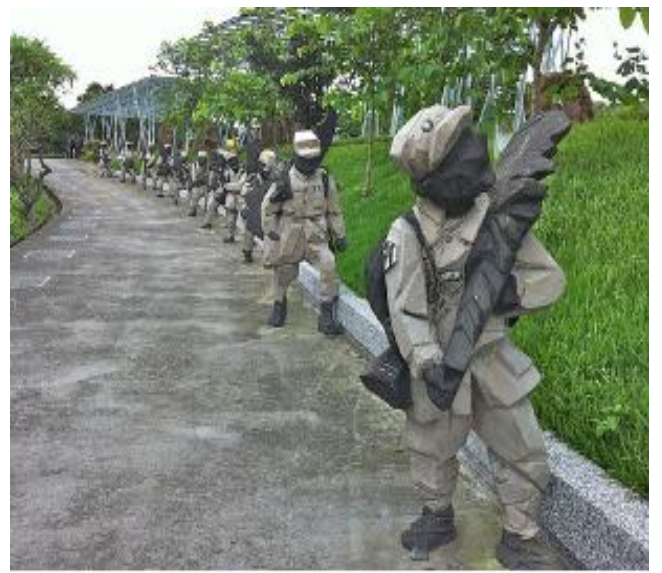

Fig. 7. Works of man's world series — the army.

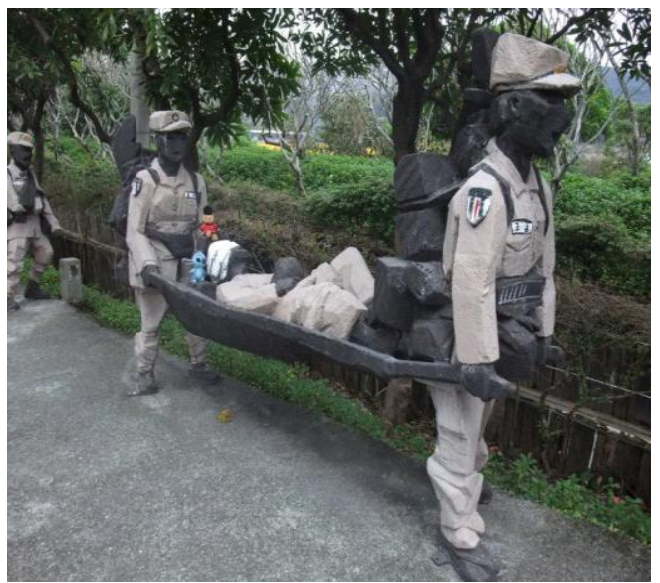

Fig. 8. Works of man's world series — the army.

One chapter in the famous book "see or not see - visual education in the era of picture-reading" specifically contrast the charm of "sightseeing" and "gaze". It says: "the vision of gaze is a vision with strong dominant and offensive. From the perspective of civilization, the vision of gaze is constructed and consolidated by Western modern rationalism, which clearly embodies the arbitrary and dictatorial domination of human subject to the natural space. There is no focus in sightseeing, so sightseeing means equality, which is the great wisdom of Chinese culture in processing the relationship with nature. ${ }^{2}$ It is obvious that the flying men who are placed highly can't achieve equal effect of other sculptures in the museum in the space position. Such difference in vision will inevitably make the audience use different viewing patterns. So why do we think this looking up is "gaze"? The premise is that the previous watch of the

2 The scenery in gazing or sight seeing of "To see or not to see visual education in the era of picture-reading" Wang Xin, New Star Press, 2014.6: 298-299. 
audience is "sightseeing", so their eyes are moving. In the "lure" of bright yellow, the people's eyes are successfully brought to the flying men. Therefore, the success of this piece of work is its position and the use of color.

The perspective of looking up breaks the viewing patterns of original flashing sightseeing, so the audience's eyes were focused on the mid-air paratroops. Passing the sculpture of fly ing men in the air, we come to the open space inside the museum, where the sculpture groups lead the audience step by step into the deepest as tour guides.

There are passers-by in "the man's world" on both sides of the road at any time. They are silent, and teach us to combine work and rest only by their behavior and teach us to remember to open the umbrella in the hot sun. The soldiers who hold the wounded have rapid pace, so that we seems to hear their breath, but this voice is so calm. Unconsciously we come to the "Tai Chi" square with the soldiers, and Tai Chi people are playing Tai Chi. Although we have no idea about what they are doing, we still cannot help following their movements to put the same shape, and then we communicate with each other.

When walking in the spaces, each audience has the mood of staying here because each person here can find their own position. In the "sightseeing", they turn into a sculpture of the little girl snuggling in the arms of her mother, watching the clouds in sky and the spectacularity of returning navy after sailing in the distant sunglow with the mother, and listening to her mother to tell her short story as shown in "Fig. 9" and "Fig. 10". The museum creates lovely and funny people to the audience, and they are all gathered here. Even the scientists who have always been regarded as serious people become cute. The role, identity, status, and political position have fled into the dirt, hidden in the bushes, and even breath sounds become cautious. The childhood that have been forgotten by us also resurges, holding by the flying men to soar between heaven and earth, and falls in a group of children playing the marbles. Then we pick up the discarded "glass ball" one by one to find the source of dreams. Humanity return to us here, and every individual here naturally generates moss that naturally fall off with the changes in time, which is as ordinary as every flesh that have to experience the birth and death.

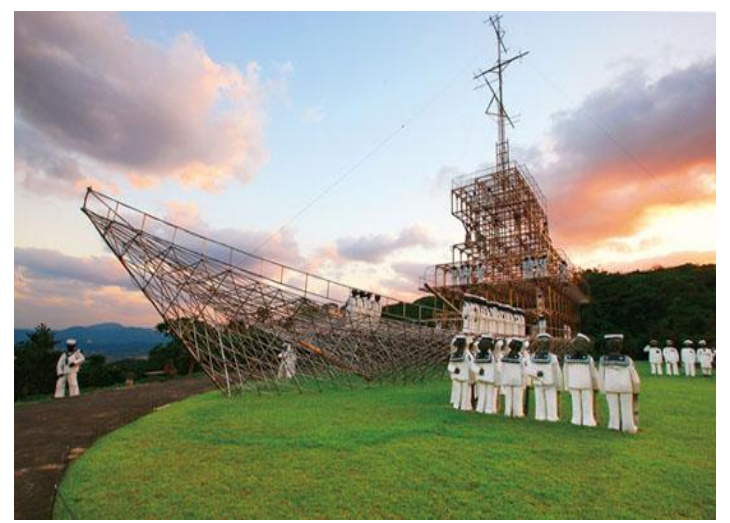

Fig. 9. Works of man's world series.

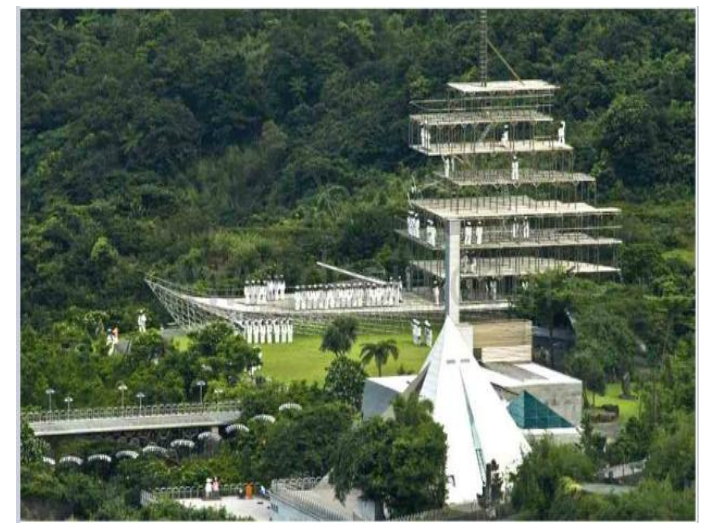

Fig. 10. Works of man's world series.

\section{ANALYZE THE "CEREMONY" IN SERIES OF}

SCULPTURE "THE MAN'S WORLD" WITH THE VISUAL W AY OF "SIGHT SEEING"

\section{A. Introduction to the Series of Sculpture "the Man's World"}

In 1981, he has been over forty years old and in middle age. He has enjoyed a reputation in Tai Wan, Hong Kong and other Asian regions. However, his heart cannot calm the upward mo mentum, so he hopes to get to a higher level. The United States is his goal. The United States as the important place for modern art always attracts him. Then he traveled across the ocean to the United Kingdom, living a difficult creative life to create the lifelike series of the man's world. During the period in the United States, Zhu Ming suffered a lot of difficulties from both the material and spirit. When he arrived in New York, he lives in the dormitory room for Taiwan students with the help of friends, but in accordance with the provisions, a person can only stay for three days. However, what to do after three days? Fortunately, the student has five classmates who can still help Zhu Ming stay. In this short buffer, Zhu Ming found the place to stay. In consideration of "cheapness", Zhu Ming had to choose the darktown outside New York, but he found problems after stay. First of all, apartments in New York are not allowed to do sculpture creation and no wood can be bought in New York. Zhu Ming fell into the situation of no place and no material at that moment. Nevertheless, for "this important time", Zhu Ming struggled through the difficulties and the express the man's world into the works.

Qiu Xixun had lived with Zhu Ming for a while, and he can feel the "spiritual suffering" of Zhu Ming because Brooklyn district is a mixed place, with "robbery" as commonplace. Zhu Ming got through in such a difficult environment. As Zhu Ming personally think that the series of works "the man's world" is the expression of sample of the diversity of the world as well as the portrayal of varied people in the life course. The loveliest place in the world lies in the transcendence of self-spiritual and attachment for the world. The series of "the man's world" is interspersed with the image of the present and the past. From plain and honest old woman to fashionable modern girl, all give out the temperament of life. 


\section{B. "Etiquette" in the Series of Sculpture "the Man's World"}

"The man's world" series works are divided into: various aspects of the man's world, the material and dialogue, new attitude to life, human series of prisoners. The materials of works include wood, stone, pottery, porcelain, copper, sponge over copper, and stainless steel and so on. Various aspects of the man's world taking the colorful world as the subject describe the diverse forms in the world; the material and dialogue uses sponge over copper, stainless steel, and stone to create works, which are mainly exaggerated and distortional figures; new attitude to life presents the current world by showing public life and fashionable girls.

The traditional Chinese character of "etiquette" is "禮". Origin of Chinese Characters says: "etiquette is like shoe, so we should behave according to etiquette in order to pray for good luck." Originally, it means holding ceremony to worship the god for good luck. “禮” is an associative compound derived from "示" and "豊". "豊" is derived from bean-like pictographs, which refers to the utensil used for worship ceremony. It is called ceremony if it is used for worship. "示" is also an associative compound. In its small seal script form, the upper part "二" is "上" of ancient characters and the bottom "小" is originally composed of three vertical lines, which represent the sun, the moon and stars. "Book of Changes" writes: "only by observing the astronomy in the sky can we have an insight into the changes in the world." This is because astronomical phenomena are the means that gods instruct the human. "示", as a radical in Chinese characters, is mainly related to worship to gods. For example: "祝" is the eulogy of Cilisinay; "福" is the shelter of gods; "禅" refers to emperor sacrificing the heaven; "社" is the god of land. Therefore, the meaning of "礼" can be comprehended by combining the above examples. In the past, "礼" mainly means the worship for gods, expression of respect, which is the important content of Confucian culture. It refers to the respect for others when extended to daily life. The Commentary of Zuo says: "etiquette is the unalterable principle as well as the behavioral norms of people" ${ }^{3}$

Etiquette not only takes everyone's need into consideration, but also emphasize on the differences between people to maintain the group structure. As the pupil of Confucius You Ruo says, "Among the application of etiquette, harmony is the most important. The governance of ancient monarchs is also valuable because of this. However, it is sometimes impractical to do everything no matter small or big according to the harmonious way. This is because it is not feasible to do everything for harmony without controlling it with etiquette." "Etiquette" values the harmony, but it can't ignore the difference. It needs to consider the hierarchical differences between emperor and courtier, and fathers and sons. This degree of "harmony" is the same understanding of the concord and kind between various relationships to the "difference".

So how do the sculptures of Zhu Ming present "etiquette"? Research
The "etiquette" in Zhu Ming's sculpture is mainly shown in the series of "the man's world", and the space layout of Zhu Ming's Art Museum also shows the word "etiquette". Queuing up in the man' world is the direct presentation of "etiquette".

Entering into the collection area of Zhu Ming's Art Museum, on the side of entrance is a group of sculptures of a long queue as shown in "Fig. 11" and "Fig. 12":

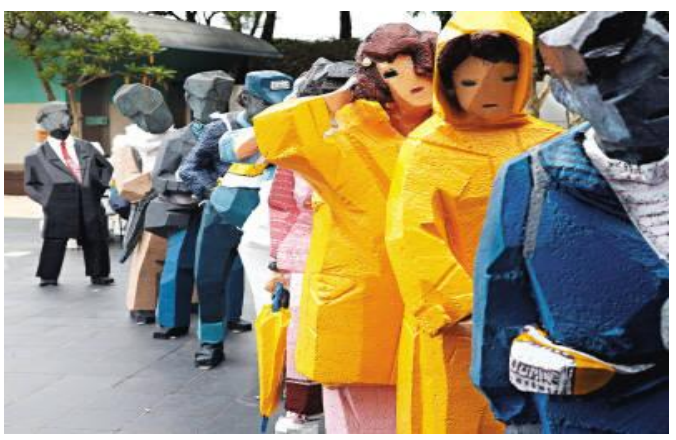

Fig. 11. The series of the man's world - queue (entrance of Zhu Ming's Art Museum)

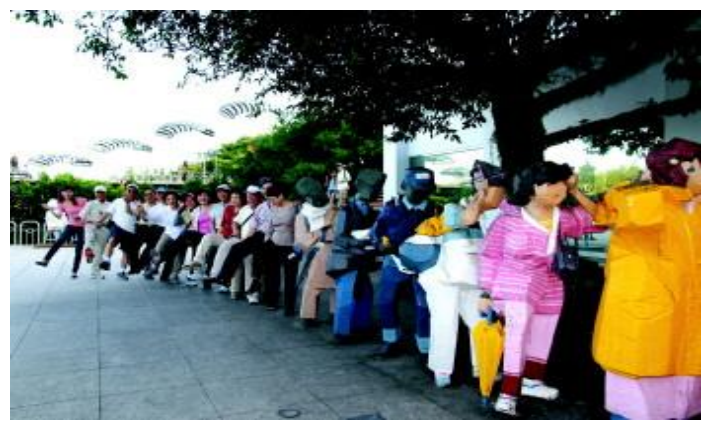

Fig. 12. The series of the man's world - queue (entrance of Zhu Ming's Art Museum) Material of master stamper: expandable poly styrene incision

The viewers of different shapes crowds around the entrance of exhibition hall, some of whom are waiting patiently and calmly, some are restless with heads looking forward at times, and some use hands to hold their neck. Then when we look at the crease of clothes of the sculptures, which expresses his mind concisely, we can faintly see the cutting marks. Sculpture applies expandable polystyrene, which is soft and light. It can reduce the consumption of physical strength to a certain extent, thereby improving the output and quality of work. Soft expandable polystyrene is very easy to cut, and after cutting, small particles and round honeycomb texture will be left, forming a natural and rich material language. At the same time, color matching of yellow and blue is clear and childish, and a vigorous picture with life extension is presented coupled with a little pink.

This group of sculptures is ingeniously integrated into the whole context of art museum, and is displayed at the entrance of museum in a queue. It is not only the beautiful scenery that decorates the art museum, but also an artistic behavior that spreads the seeds of "etiquette". The sculptures guide the viewer to the "etiquette" with its silent way. The regieren of The Analects of Confucius argues that: 
Confucius said: "if you use legal prohibition to guide the people and use criminal law to restrain them, the people will just seek freedom from punishment, but lose the sense of shame; if you guide the people with moral education and unify the words and deeds of the people by using etiquette, the people will only have the sense of shame, but also follow the rules." Mr. Qian Mu calls it Confucius political thoughts in the "New Explanation on The Analects of Confucius", which advocate moralization and etiquette system. The general idea is that it is more effective to use the etiquette to govern people than the criminal law. Mr. Zhu Ming's "queuing" sculptures group just echoes this point.

Here the work "series of the man's world - prisoners" is specifically analyzed: it is composed of three parts of "prisoners", "good and evil" and "marriage" as in "Fig. 13", "Fig. 14", "Fig. 15", and "Fig. 16" symbolizing three philosophy of life of imprisoning, imprisoned, self-crime. From the perspective of the contents, this group of works is more like censuring "etiquette". The works complain the civilized etiquette system of "the appropriate sense of righteousness between sovereign and minister, kinship between father and son, the attention paid to the proper and different roles of husband and wife, respect for seniority, faithfulness between friends." , instead of promoting "etiquette" as described previously. The prisoners were imprisoned by the jail of the rule of law. Being imprisoned by the "etiquette" of civilized rulers in good and evil makes they can't do what they want to do freely. The etiquette of marriage is like a shackle that binds two separate persons who will have to be tortured by marriage and family. On the surface, it seems that this understanding is right, but when we return to the initial construction of "etiquette", the theory of bundle in the previous text clearly can't make sense. Ancient China regards blood relationship and marriage as the most important things. According to the "uncle and aunt" in the chapter of "mourning without stick" in "etiquette: the commentaries on mourning apparel", it says that father and mother are close, husband and wife are close and brothers are close. Therefore, the relationship between father and son is like that of head and feet; the relationship between husband and wife is like that of the two part of body; the relationship between brothers is like that of arms and legs.

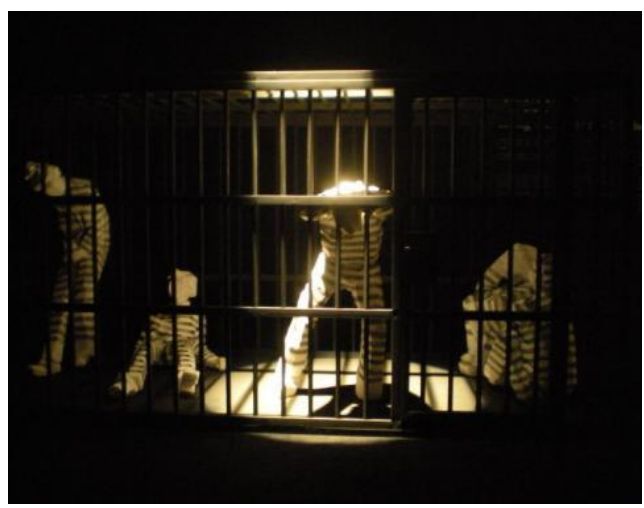

Fig. 13. The "prisoner"

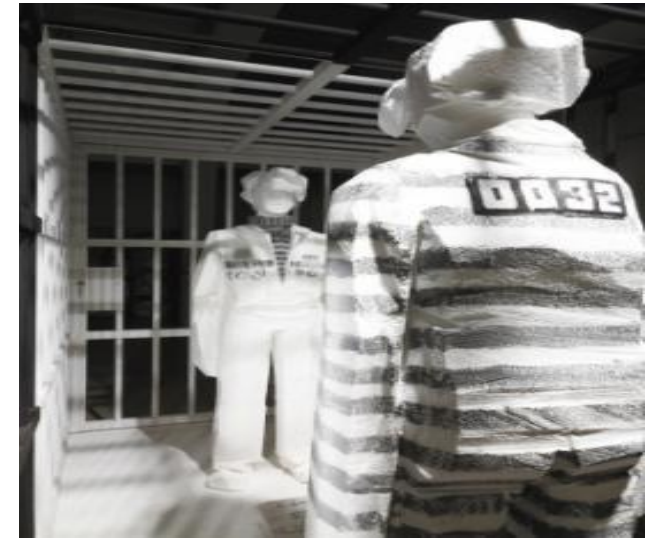

Fig. 14. The picture "good and evil". (Pure white for good, black stripes for evil)

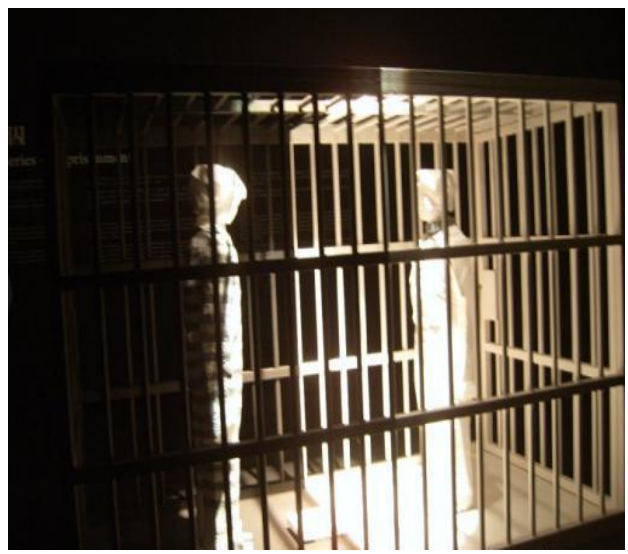

Fig. 15. The "prisoner".

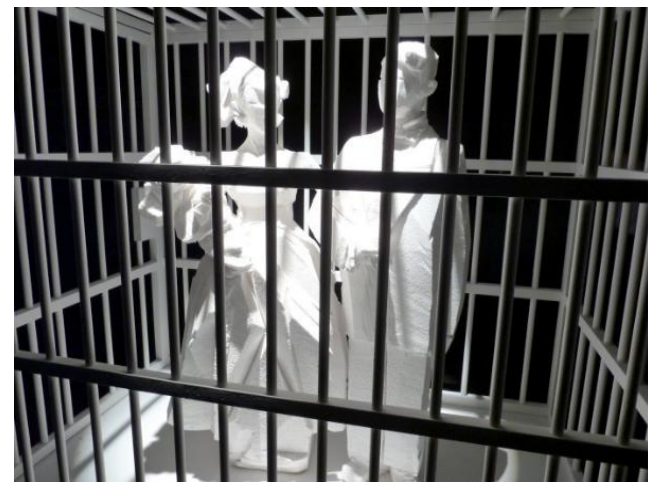

Fig. 16. The picture "marriage".

"Yi Zhuan: orderly sequence" says: the heaven and earth generate all things on earth; then man and woman are generated; then husband and wife appear; then there are father and son; after that there are emperor and courtiers; then hierarchy is generated, which generates ritual and etiquette."

"The Book of Rites" says: "ritual of marriage": the man and woman are different, and they have their obligation; then father and son have blood relationship, and emperor and courtiers have their own position." 
The Book of Rites: Jiaotesheng says that the man and woman are different, then father and son have blood relationship, morality is generated, and finally etiquette is adopted. When etiquette is adopted, everything will be in peace. If there is no difference or morality, it is the principle of animals. " 4

From the above description, we can see the keywords like "husband and wife", "sequence", and "etiquette and morality" and so on. Why are they selected? Of course, it is because these keywords provide us with the understanding about "marriage" and "etiquette" in ancient China. It is not hard to find that the initial "marriage" is not like "marriage is the tomb of love as the understanding of modern." Marriage is the product of "difference between men and women," which is completed in "etiquette and morality". Here, we cannot help asking: is it related to the content that the works of Mr. Zhu Ming intend to express? Of course yes. What the series of "prisoner" of Mr. Zhu Ming's series really wants to censure is not the "marriage" and "etiquette" themselves, but the "marriage" system under the "collapse of etiquette. The so-called "sequence" refers to the order. The type of "marriage is the love of the grave" is the "marriage" without a sequential start, which of course will become a cage that imprisons oneself. That is no "sequence". And everything in the world alternately operates in the "sequence ".

\section{CONCLUSION}

The author explores the aesthetic characteristics and cultural connotation of Zhu Ming's Art Museum from the two visual methods of "up-and-down observation" and "sightseeing". Zhu Ming transforms his works from multidimensional space, generating the visual methods of horizontal watch, watch in distance and watch around from "up-and-down observation", and he integrate the artistic spirit of "up-and-down observation to the world" and the traditional Chinese "etiquette" civilization into his works. He skillfully places separate works in the space of the museum, making the recipient get zero distance contact with the work to evoke the desire of recipients for the art its elf and help them make for the origin of art. The reasons why this article chooses Zhu Ming's Art Museum as the research object are as following:

- Zhu Min's folk wood carving is a successful case of folk wood carving transforming to elite art, which can provide elite art with a reference of art history.

- The audience can receive the natural and childish ease brought by works of art from the intuitive experience.

- The childish and natural comfort in Zhu Ming's sculptures is totally a kind of external performance. He integrates everything between people, between man and nature, and between heaven and earth, which

\footnotetext{
4 Zeng Yi: "On the reality of the Confucian classics" — taking third judicial interpretation of "The new marriage law" in mainland China as the example", published on Confucian online; the original publication is from "Confucian theory and application: collected papers for fifth anniversary of the death of Mr. Kong Decheng "(2015)" of Taiwan's Academia Sinica.
}

are gathered in the Zhu Ming's Art Museum, forming the state of "harmony". It is just as the tai chi fist position, of which every movement can be controlled freely.

- The sculptures of Zhu Ming contain Confucian culture: "etiquette". From Confucianism we know that "etiquette" plays an important role in maintaining order, so art works also need "etiquette".

- Zhu Ming follows the surrounding, and observes the heaven and earth to take heaven and earth as teachers.

\section{REFERENCES}

[1] Wang Xin. "To see or not to see - visual education in the era of picture-reading", New Star Press, 2014.6.

[2] Zeng Yi. On the reality of the Confucian classics-taking third judicial interpretation of "The new marriage law" in mainland China as the example.

[3] http://www.rujiazg.com/ 